\title{
A comparative study on the effects of various factors to the prevalence of pelvic inflammatory disease in North central Nigeria
}

\author{
Oyedum U.M. ${ }^{1}$, Kuta F.A. ${ }^{1}$, Saidu A.N. ${ }^{1}$, Babayi H. ${ }^{1}$ \\ ${ }^{1 *, 1}$ Department of Microbiology, School of Life Sciences, Federal University of Technology, Minna, Nigeria \\ ${ }^{1 *}$ Corresponding author's email: $\underline{\text { hemdi41@gmail.com }}$
}

Received: 10 December 2020 / Accepted: 26 May 2021 / Published online: 30th June 2021

\begin{abstract}
Pelvic inflammatory disease is a gynaecological disease that affects the upper genital organs of reproductive age females. It is a disease associated with clinical sequalae such as tubal blockage, oophoritis and cervicitis which are said to result to high rate of disease (such as female infertility) and deaths among the females. This study therefore attempts to evaluate the association of various factors to high prevalence of pelvic inflammatory disease among women residing in developing countries such as Nigeria. Questionnaires were administered to all women enrolled for this study too obtain their data. Seven hundred and twenty (720) patients out of 1170 patients enrolled for this study were recorded to be pelvic inflammatory disease patients, of which $380(85 \%)$ were rural dwellers; $452(87.6 \%)$ were ignorant of pelvic inflammatory disease and were thus easily prone to the disease; $285(86.4 \%)$ were within the reproductive ages of 25-29 years; $350(85.2 \%)$ previously had urinary tract infection a year ago; 496(85.8\%) and 343(83.5\%) were both married and uneducated females. The high prevalence of pelvic inflammatory disease recorded in this study is due to certain predisposing factors practiced among females in their reproductive ages, hence it is necessary for government to enforce certain measures such as establishment of free education, continuous awareness of pelvic inflammatory disease and establishment of free medical check up to help prevent and control the spread of pelvic inflammatory disease.
\end{abstract}

Keywords: Pelvic inflammatory disease, genital organs, tubal blockage, infertility.

\section{INTRODUCTION}

Pelvic inflammatory disease (PID) is basically a disease of various organs (such as the ovaries, fallopian tubes, uterus and endometrium) located in the upper genital tracts of a female. However, this disease is one of the top three prevalent gynaecological problems associated with female reproductive damages such as fallopian tubal blockage, endometriosis and oophoritis which in turn leads to $10 \%$ infertility and $0.5 \%$ mortality among women in the reproductive ages of 25-34 years (Usman, 2016). The emergence of this life threatening disease is basically associated with organisms referred to as urogenital pathogens (Naaz et al., 2016).

Overtime urogenital pathogens especially members of enterobacteriaceae such as: Escherichia coli, Salmonella spp., Klebsiella spp., Pseudomonas spp., Staphylococcus spp., and Proteus spp. (Meštrović, 2017) have been regarded as causative agents of PID in most developing countries such as Nigeria.

Previous studies have shown high prevalence of PID among rural populated women in Asia and Indian (Pachori \& Kulkarni, 2016; Naaz et al., 2016), hence it is therefore imperative to determine other predisposing factors associated with the prevalence of PID among patients attending various general hospitals in Africa, especially the North Central, Nigeria.

\section{MATERIALS AND METHODS}

\section{Study design}

Endocervical swabs and urine samples were collected from each patient diagnosed of PID, who was enrolled for this 
study, in nine government hospitals located in different Local Government Areas (LGAs) namely: Lapai, Bida, Agaie, Minna, Suleja, Kuta, Kontogora, Zungeru and Nasko. These hospitals in each Local Government Area serve as primary health care centers. The samples were collected from October 2018 to October 2019.

\section{Inclusion and exclusion criteria}

Female patients within the age of 15-54 years diagnosed of PID and attendees of the selected hospitals were recruited for this study. Female patients above 54 years and less than 15 years not diagnosed of PID and who were not attendees of the selected hospitals were excluded from this study.

\section{Ethical clearance}

Ethical clearance for this study was sought from the Niger State Hospital Management board, Research and Ethics Committee.

\section{Study population}

The study population was categorized into two groups namely: outpatients, who were clinically diagnosed of pelvic inflammatory diseases (but were not yet admitted); and in patients, who were diagnosed of pelvic inflammatory diseases and admitted (Pachori \& Kulkami, 2016; Oseni et al., 2017).

\section{Sample size}

The number of samples to be collected was calculated using the equation below (Idakwo, 2015).

$$
n=\underline{t}^{\underline{2}} \times \frac{p(1-p)}{m^{2}}
$$

Where

$\mathrm{n}=$ required sample size

$\mathrm{t}=$ Confidence level at 95\% (standard value of 1.96)

$\mathrm{P}=$ Prevalence rate of bacterial infection in Niger state (9.3\%) (Source, Niger State Ministry of Health) $\mathrm{m}=$ Margin of error at $5 \%$ (Standard value of 0.05 ) $\mathrm{n}=\left(1.96^{2} \times 0.093 \times 0.907\right) / 0.05^{2}=129.6 \cong 130$

The sample size for each L.G.A was $(\mathrm{n})=130$. Therefore, the total samples to be collected will be 1170 .

\section{Collection of demographic and clinical data}

A questionnaire was administered to obtain patient's demographic data and risk factors as described by Kolo (2017).

\section{Collection and transportation of samples}

Swab samples: Sterile flexible swab sticks were used for the collection of swab samples from the endocervical region of each patient enrolled for the study (Einwalter, 2005). The swabs were submerged into normal saline and taken to the Microbiology Laboratory of Federal University of Technology, Minna at room temperature for further analysis (Enwa et al., 2015).

Urine samples: $5-10 \mathrm{ml}$ of fresh urine samples was collected from each female patient diagnosed of PID into a universal bottle. The urine samples were transported to the Microbiology Laboratory of Federal University of Technology, Minna using an ice pack (Hunter et al., 2013). The urine samples were stored at $4^{\circ} \mathrm{C}$ for 24 hours (Hunter et al., 2013).

\section{Direct examination}

Saline wet preparation was carried out in order to rule out the presence of Trichomonas vaginalis which is characteristically associated with a yellow-green discharge, itching, redness and swelling (Spencer et al., 2014).

\section{Culture of bacteria}

The endocervical swabs and urine samples were cultured and incubated on the media such as Nutrient agar, MacConkey agar, chocolate agar and Salmonella-Shigella agar at $37^{\circ} \mathrm{C}$ for 24 hours for the isolation of Gram negative and Gram positive bacteria. Pure cultures of each isolates were obtained by continuous sub-culturing using the streak method. The pure isolates were stored on a nutrient agar slant for further identification and characterization.

\section{Data analysis}

The data obtained were analyzed using Chi-square.

\section{RESULTS}

\section{Occurrence of Pelvic Inflammatory Disease (PID) in 9 general hospitals}

The percentages of PID in nine general hospitals in Niger state, is shown in Table 1 . The result obtained revealed that out of 1170 female patients sampled 720(62\%) were the positive cases while $450(38 \%)$ were the negative cases.

Table 1: Percentage of positive cases of PID in nine general hospitals

\begin{tabular}{lll}
\hline NSS & NPS & NNS \\
\hline 1170 & $720(62 \%)$ & $450(38 \%)$ \\
\hline
\end{tabular}

Key:

NSS: Number of samples screened

NPS: Number of positive samples

NNS: Number of negative samples 
Table 2: Prevalence of PID in relation to settlement

\begin{tabular}{lcccc}
\hline Settlement & NSS & NPS & NNS & $\chi$ 2(p-value) \\
\hline Urban & 723 & $340(47.0)$ & $383(53.0)$ & \\
Rural & 447 & $380(85)$ & $67(15.0)$ & $168.387(0.00)$ \\
\hline
\end{tabular}

Table 3: Prevalence of PID in relation to awareness

\begin{tabular}{lcccc}
\hline Awareness & NSS & NPS & NNS & $\chi 2(p$-value) \\
\hline Yes & 654 & $268(40.9)$ & $386(59.0)$ & \\
No & 516 & $452(87.6)$ & $64(12.4)$ & $213.238(0.00)$ \\
\hline
\end{tabular}

Table 4: Prevalence of PID in relation to age

\begin{tabular}{lcccc}
\hline Age & NSS & NPS & NNS & $\chi^{2}(\mathrm{p}$-value $)$ \\
\hline$<15$ years & 79 & $18(22.8)$ & $61(77.2)$ & \\
$15-19$ years & 187 & $118(63.1)$ & $69(36.9)$ & \\
$20-24$ years & 183 & $119(65.0)$ & $64(35.0)$ & \\
$25-29$ years & 330 & $285(86.4)$ & $45(13.6)$ & \\
$30-34$ years & 159 & $102(64.2)$ & $57(35.8)$ & \\
$35-39$ years & 96 & $40(41.7)$ & $56(58.3)$ & \\
$40-44$ years & 75 & $17(22.7)$ & $58(77.3)$ & \\
$45-49$ years & 43 & $18(41.8)$ & $25(58.1)$ & \\
$>50$ years & 18 & $3(16.6)$ & $15(83.3)$ & $212.396(0.00)$ \\
\hline
\end{tabular}

Tables 5 and 6: Prevalence of PID in relation to previous PID and Sexually Transmitted Disease

\begin{tabular}{lcccc}
\hline Previous PID & NSS & NPS & NNS & $\chi^{2}(\mathrm{p}$-value $)$ \\
Yes & 478 & $115(24.0)$ & $363(76.0)$ & \\
No & 692 & $605(87.4)$ & $87(12.6)$ & $498.464(0.00)$ \\
& & & & \\
\hline Previous STI & & & & \\
Yes & 529 & $176(33.3)$ & $353(66.7)$ & \\
No & 641 & $544(84.9)$ & $97(15.1)$ & $335.084(0.00)$ \\
\hline
\end{tabular}

Table 7: Prevalence of PID in relation to previous abortion

\begin{tabular}{lcccc}
\hline Previous Abortion & NSS & NPS & NNS & $\chi^{2}(p$-value $)$ \\
\hline Yes & 544 & $212(39.0)$ & $332(61.0)$ & \\
No & 626 & $508(81.1)$ & $118(18.8)$ & $233.163(0.00)$ \\
\hline
\end{tabular}

Table 8: Prevalence of PID in relation to previous urinary tract infection

\begin{tabular}{lcccc}
\hline Previous UTI & NSS & NPS & NNS & $\chi^{2}(p$-value $)$ \\
\hline Yes & 868 & $578(66.6)$ & $290(33.4)$ & \\
No & 302 & $142(47.0)$ & $160(53.0)$ & $157.706(0.00)$ \\
\hline
\end{tabular}




\section{Factors associated with the occurrence of PID}

The occurrence of PID among women of various locations is as shown in Table 2. The result showed that out of 1170 women sampled, women residing in the rural areas, who were $380(85 \%)$ had a significantly higher case of the infection $(\mathrm{p}<0.05)$ than women residing in the urban locations $340(47.0 \%)$. There was a significant $\left(\mathrm{X}^{2}=168.387, \mathrm{p}=0.00\right)$ difference in the PID occurrence between the various location of residents. Table 3 reveals the association between awareness and the occurrence of PID. $452(87.6 \%)$ of the female patients sampled had no knowledge of PID while 268(40.9\%) of the sampled population had knowledge of the disease. However, there was a significant $\left(\mathrm{X}^{2}=213.238, \mathrm{p}=0.00\right)$ association between awareness and the occurrence of PID. The prevalence of PID in relation to age is presented in Table 4. Out of the 1170 women sampled. Women within the age bracket of 25-29 years, who were $285(86.4 \%)$ had a higher occurrence of PID compared with other age groups such as 20-24 years, 15-19 years and 30-34years who had 119(65.0), 118(63.1) and 102(64.2) respectively. There was a significant $(X=212.396, p=0.00)$ association between the various age brackets and the occurrence of PID.

Prevalence of PID in relation to the patient's previous PID and Sexually Transmitted Disease status is presented in Tables 5 and 6 respectively. These tables revealed that women who had never had PID, 605(87.4\%) and STI, 544(84.9\%) had higher occurrence of the disease than women who had been previously exposed to PID $115(24.0 \%)$ and STI 176(33.3\%). There was a significant $\left(\mathrm{X}^{2}=498.464, \mathrm{p}=0.00 ; \mathrm{X}^{2}=335.084, \mathrm{p}=0.00\right)$ association between the previous status of PID and STI and the occurrence of the disease. Table 7 presents the relationship between the previous status of abortion in relation to the occurrence of PID. 508(81.2\%) of women with no previous abortion had higher significant occurrence of the infection $(\mathrm{p}<0.05)$ than women who had performed abortion $138(44.4 \%)$. There was a significant $\left(X^{2}=\right.$ 233.163, $\mathrm{p}=0.00$ ) association between no previous abortion practices and the occurrence of the disease. Table 8 presents prevalence of PID with regards to the urinary tract infection (UTI). Out of the 1170 women sampled, $578(66.6 \%)$ of women who had the disease had higher infection rate than women 142(47.0) who had never had UTI. There was a significant $\left(\mathrm{X}^{2}=157.706, \mathrm{p}=0.00\right)$ association between the UTI and the occurrence of PID.

The prevalence in relation to marital status is shown in Table 9. The result showed that married women $502(86.9 \%)$ had the highest occurrence of the infection than single women $218(36.8 \%)$. There was a significant $\left(\mathrm{X}^{2}=212.151, \mathrm{p}=0.00\right)$ difference between the occurrence of PID and the various marital status. Table 10 revealed that out of 1170 women sampled $382(88.0 \%)$ of women who were into polygamous family had the infection followed by 248(45.2\%) of women who had no family status and then the least group of women affected with the infection are those into monogamous family status 90(47.4\%). There was a significant $\left(\mathrm{X}^{2}=161.929, \mathrm{p}=0.00\right)$ association with regards to the various family status and the occurrence of PID.

Table 11 presented the association between occupation and the occurrence of PID. 384(85.7\%), 222(63.4\%) and $114(30.6 \%)$ were the unemployed, student and educated women who were infected with PID. However, there was a significant $\left(X^{2}=254.454, p=0.00\right)$ association between occupation and the occurrence of PID. The prevalence of PID in relation to education is presented in Table 12. Out of the 1170 women sampled, uneducated women had the highest occurrence of infection 343(83.5\%) followed by women with primary education $216(66.5 \%)$, women with secondary education $108(44.3 \%)$ and women with tertiary education 53(27.9\%) were the least affected. There was a significant $\left(\mathrm{X}^{2}=206.041, \mathrm{p}=0.00\right)$ association between the various education status and the occurrence of PID.

Table 13 shows the effect of douching frequency on the prevalence of PID. Women 519 (88.3\%) that douche daily had the highest occurrence of the disease followed by women $201(37.6 \%)$ that douche weekly. There was a significant $\left(X^{2}=383.112, p=0.00\right)$ association between the douching frequency and the occurrence of the disease. Table 14 presents the relationship between the douching products and the occurrence of PID. 360(72.4\%), $194(57.7 \%)$ and $166(49.3 \%)$ of women used water, water and soap and other materials for douching. There was a significant $\left(\mathrm{X}^{2}=48.453, \mathrm{p}=0.00\right)$ association between various douching products and the disease. Table 15 presents prevalence of PID with regards to the water sources. Women who used river water $304(80 \%)$ had the highest infection followed by women who used well $187(63.4 \%)$ and tap water $161(57.1 \%)$ respectively. There was a significant $\left(\mathrm{X}^{2}=183.568, \mathrm{p}=0.00\right)$ association between various water sources and the disease.

The prevalence in relation to toilet facilities is presented in Table 16. The result showed that women 411(79.2\%) who defecated in the open environment had the highest occurrence of the infection than women $180(54.3 \%)$ and $87(27.2 \%)$ who used pit latrine and water closet respectively. There was a significant $\left(\mathrm{X}^{2}=280.270, \mathrm{p}=0.00\right)$ difference in the occurrence of PID between the various toilet facilities users. 
Table 9: Prevalence of PID in relation to marital status

\begin{tabular}{lcccc}
\hline Marital Status & NSS & NPS & NNS & $\chi^{2}$ (p-value) \\
\hline Single & 592 & $218(36.8)$ & $374(63.2)$ & \\
Married & 578 & $502(86.9)$ & $76(13.1)$ & $212.151(0.00)$ \\
\hline
\end{tabular}

Table 10: Prevalence of PID in relation to family status

\begin{tabular}{lcccc}
\hline Family Status & NSS & NPS & NNS & $\chi^{2}$ (p-value) \\
\hline N.F.S & 546 & $248(45.2)$ & $298(54.6)$ & \\
Monogamy & 190 & $90(47.4)$ & $100(52.6)$ & \\
Polygamy & 434 & $382(88.0)$ & $52(12.0)$ & $161.929(0.00)$ \\
\hline
\end{tabular}

Table 11: Prevalence of PID in relation to occupation

\begin{tabular}{lcccc}
\hline Occupation & NSS & NPS & NNS & $\chi^{2}$ (p-value) \\
\hline Unemployed & 448 & $384(85.7)$ & $64(14.3)$ & \\
Student & 350 & $222(63.4)$ & $128(36.6)$ & \\
Employed & 372 & $114(30.6)$ & $258(69.4)$ & $254.454(0.00)$ \\
\hline
\end{tabular}

Table 12: Prevalence of PID in relation to education

\begin{tabular}{lcccc}
\hline Education & NSS & NPS & NNS & $\chi^{2}$ (p-value) \\
\hline Uneducated & 411 & $343(83.5)$ & $68(16.5)$ & \\
Primary education & 325 & $216(66.5)$ & $109(33.5)$ & \\
Secondary education & 244 & $108(44.3)$ & $136(55.7)$ & \\
Tertiary education & 190 & $53(27.9)$ & $137(72.1)$ & $206.041(0.00)$ \\
\hline
\end{tabular}

Table 13: Prevalence of PID in relation to douching frequency

\begin{tabular}{lcccc}
\hline Douching Frequency & NSS & NPS & NNS & $\chi^{2}(\mathrm{p}$-value $)$ \\
Daily & 588 & $519(88.3)$ & $69(11.7)$ & \\
Weekly & 534 & $201(37.6)$ & $333(62.4)$ & \\
Monthly & 37 & $0(0.00)$ & $37(100)$ & \\
Yearly & 11 & $0(0.00)$ & $11(100)$ & \\
Not Practiced & 0 & $0(0.00)$ & $0(0.00)$ & $383.112(0.00)$ \\
\hline
\end{tabular}

Table 14: Prevalence of PID in relation to douching products

\begin{tabular}{lcccc}
\hline Douching Products & NSS & NPS & NNS & $\chi^{2}(\mathrm{p}$-value) \\
Water Only & 336 & $194(57.7)$ & $142(42.3)$ & \\
Water and Toilet Soap & 497 & $360(72.4)$ & $137(27.6)$ & \\
Others & 337 & $166(49.3)$ & $171(50.7)$ & $48.453(0.00)$ \\
\hline
\end{tabular}

Table 15: Prevalence of PID in relation to water source

\begin{tabular}{lcccc}
\hline Water Source & NSS & NPS & NNS & $\chi^{2}$ (p-value) \\
Borehole & 216 & $48(22.2)$ & $168(77.8)$ & \\
Tap & 282 & $161(57.1)$ & $121(42.9)$ & \\
Well & 261 & $187(63.4)$ & $108(36.6)$ & \\
River & 380 & $304(80)$ & $76(20)$ & \\
Others & 31 & $20(64.5)$ & $11(35.5)$ & $183.568(0.00)$ \\
\hline
\end{tabular}


Table 16: Prevalence of PID in relation to toilet facilities

\begin{tabular}{lcccc}
\hline Toilet Facility & NSS & NPS & NNS & $\chi^{2}($ p-value $)$ \\
\hline Water Closet & 320 & $87(27.2)$ & $233(72.8)$ & \\
Pit Latrine & 331 & $180(54.3)$ & $151(45.6)$ & \\
Open Air & 519 & $411(79.2)$ & $108(20.8)$ & $280.270(0.00)$ \\
\hline
\end{tabular}

Table 17: Prevalence of PID in relation to practice of birth control

\begin{tabular}{lcccc}
\hline Practice of Birth Control & NSS & NPS & NNS & $\chi^{2}$ (p-value) \\
\hline Yes & 523 & $277(53.0)$ & $246(47.0)$ & \\
No & 647 & $443(68.4)$ & $204(31.5)$ & $28.986(0.00)$ \\
\hline
\end{tabular}

Table 18: Prevalence of PID in relation to types of birth control

\begin{tabular}{lcccc}
\hline Types of Birth Control & NSS & NPS & NNS & $\chi^{2}(\mathrm{p}$-value $)$ \\
\hline Abstinence & 47 & $9(19.1)$ & $38(80.9)$ & \\
Intrauterine device & 235 & $126(53.6)$ & $109(46.4)$ & \\
Pills & 121 & $49(40.5)$ & $72(59.5)$ & \\
Condoms & 235 & $116(49.4)$ & $119(50.6)$ & \\
No type used & 532 & $420(78.9)$ & $112(20.7)$ & $150.603(0.00)$ \\
\hline
\end{tabular}

Table 19: Prevalence of PID in relation to self medication

\begin{tabular}{lcccc}
\hline Self-Medication Practice & NSS & NPS & NNS & $\chi^{2}($ p-value $)$ \\
\hline Yes & 625 & $556(89.0)$ & $69(11.0)$ & \\
No & 545 & $164(30.1)$ & $381(69.9)$ & $426.265(0.00)$ \\
\hline
\end{tabular}

Table 20: Prevalence of PID in relation to drug dosage

\begin{tabular}{lcccc}
\hline Drug Dosage Practice & NSS & NPS & NNS & $\chi^{2}(\mathrm{p}$-value $)$ \\
\hline Complete Dosage & 601 & $225(37.4)$ & $376(62.6)$ & \\
Incomplete Dosage & 569 & $495(87.0)$ & $74(13.0)$ & $303.277(0.00)$ \\
\hline
\end{tabular}

Table 17 presented the association between birth control practices and the occurrence of PID. 277(53.0\%) of women who practiced birth control were infected with PID while 443(68.4\%) who were highly infected showed they never practiced birth control. However, there was a significant $\left(\mathrm{X}^{2}=28.986, \mathrm{p}=0.00\right)$ association between birth control practices and the occurrence of PID. The prevalence of PID in relation to the various types of birth control is presented in Table 18. Out of the 1170 women sampled, women who never used any type of birth control had the highest occurrence of infection 420(78.9\%) followed by women who used intrauterine device 126(53.6\%) and condom 116(49.4\%) with PID occurrence. There was a significant $\left(\mathrm{X}^{2}=150.603, \mathrm{p}=0.00\right)$ association between the various birth control and the occurrence of PID.

The prevalence in relation to self medication is shown in Table 19. The result showed that women that practiced self medication 556(89.0\%) had the highest occurrence of the infection than women who never indulged in self medication $164(30.1 \%)$. There was a significant ( $\mathrm{X}=426.265, \mathrm{p}=0.00)$ difference between self medication and PID caused by resistant bacteria.

Table 20 presented the association between drug dosage and the occurrence of PID. 225(37.4\%) practiced complete dosage of drugs while $495(87.0 \%)$ practiced incomplete dosage of drugs.

\section{DISCUSSION}

Pelvic inflammatory disease is basically the disease of female genital organs. It is usually said to occur when bacteria ascends from the vagina to the upper genital tract. This disease is regarded as various inflammations such as cervicitis, endometritis, oophoritis and salpingitis which occur in the female genital tract. However, when cases are complicated, there are severe consequences and these in turn lead to infertility.

The high prevalence of bacterial organisms associated with 
PID patients (as seen in Table 1) is due to the fact that most women experience silent spread of the infection to the upper genital tract which results to PID infection without their knowledge. Most women are associated with this infection but are not aware of this because women with the infection show no signs and symptoms and are usually undiagnosed and this therefore results to high degree of damages (such as miscarriage, preterm labor, ectopic pregnancy and infertility) in the infected females (Naaz et al., 2016). This is in agreement with the findings of (Naaz et al., 2016; Pachori \& Kulkarni, 2016) who revealed that higher rates of PID infection are observed in Africa followed by Asia and then India which have percentage rates of $60 \%, 57 \%$ and $30 \%$ respectively. Similarly, this result agrees with the findings of Shinde et al. (2018) who observed that all 200(100\%) women sampled had PID infection. However, this study disagrees with the findings of French et al. (2011) and Huang et al. (2019) who estimated the prevalence rate of PID infection to be $1.6 \%$ and $2 \%$ respectively.

The high prevalence of PID among rural dwellers is due to the fact that most of these rural women are ignorant of symptoms associated with PID due to lack of standard health care facilities which is said to be a normal experience for most rural dwellers. Such women only visit urban health facilities when cases are critical which may in turn lead to death. This finding agrees with Dayal (2016) who stated that all the 247(100\%) PID cases sampled in India were collected from rural settlement and in disagreement with study of Usman (2016) who stated that $72.3 \%$ of the patients were from the urban setting compared to $27.2 \%$ who were from the urban settings.

The high prevalence of PID among women who had no knowledge of PID infection is since most of these women studied were illiterate and are mostly from poor socioeconomic background which therefore renders the women helpless and not up to date to certain health issues. In addition to this most women are not aware of this disease because many times the disease occurs as an asymptomatic, but when the disease occurs as a symptomatic, affected women feel reluctant to discuss their reproductive health challenges for fear of stigmatization. Usman (2016) stated that $67.7 \%$ of PID cases were aware of the disease while $32.7 \%$ cases are not aware. This result is also in agreement with the result of Saini et al. (2003).

High prevalence of PID among women within 25-29 years could be attributed to the fact that PID is an infection that affects young, sexually active and reproductive age women in society. In addition to this, these young women possess cervix which contain cervical mucus which lacks antimicrobial properties and has high permeability status.
Also, the host-immune system in these younger women is usually weak compared older women. This finding agrees with Naaz et al. (2016) who stated maximum number of women sampled in a study was between the ages of 25-29 years. This result is also in agreement with Shinde et al. (2018) and Ahmed et al. (2017) who reported 26.5\% and $54 \%$ of females in the age brackets between 25-29 years and 26-35years respectively had PID and explained that constant indulgence in sexual relationships among young ladies lead to high PID infection rate. This result is in disparity with the findings of Dayal (2016) who reported the highest PID infection to be within the ages of 31-40 years.

Women who never had episodes of PID infection revealed high prevalence of PID among them and this could be based on certain characteristics such as high frequency of partner change (who might have infections in them), no adequate skills and no confidence to negotiate safe sex which in turn lead to higher chances of PID among the women. However, women who had 115(24.0\%) repeated episodes of PID after the initial exposure to PID is because most of these women cannot adhere to preventive health care tips and as such depend on multiple partners for survival. This finding is in agreement with Simm (2006).

Similarly, women who had never had STI who showed higher prevalence of PID could be attributed to the fact that PID is a polymicrobial infection which can occur when ascension of bacteria from the lower genital tract to upper genital tract is supported through unhygienic process that enhances bacterial vaginosis (abnormal microbial growth around the vagina). In addition, most these women might have practiced constant abortions, hence the introduction of microbes from external sources into the female pelvic region which in turn subjects the women causes PID. This result is in agreement with Ahmed et al. (2017).

This study also revealed that women with PID had never had abortion. This could be based on the fact that most of these women who occur in the rural areas depend primarily on untrained or less trained birth attendants and relatives for assistance during childbirth. Such unqualified attendants, conduct the delivery process in very unhygienic environment (such as patient's home or dirty hospital environment), never use any sterile gloves and conduct repeated examinations (with their bare hands) even after rupture of the membrane. This gives an opportunity for potential pathogens to pass from the lower genital tract into the normally sterile environment of uterus. This finding disagrees with Ahmed et al. (2017) who stated that $50(33.33 \%)$ out of 150 patients sampled practiced unsafe abortion which is a potential source for the entrance of pathogens. 
Women who had recurrent cases of urinary tract infections (UTI) had higher cases of PID compared to women who never had urinary tract infections. This could be based on the fact that the urinary tract (which shows high proximity to the female genital organs) as well as the intestinal bowels is also a habitat for most opportunistic organisms such as the anaerobes which are the main aetiological agents for most PID (such as salpingitis) (Naaz et al., 2016). In addition, anatomic changes induced by pregnancy and delivery contribute to an easier access of bowel flora to the vagina. This may lead to an increased occurrence of a type of PID in women of comparatively higher age. This finding agrees with Ahmed et al. (2017) who stated that all the 247 (100\%) PID cases sampled in India were collected from rural settlement and in disagreement with study of Usman (2016) who stated that $72.3 \%$ of the patients were from the urban setting compared to $27.2 \%$, who were from the urban settings.

This study showed that women who are married had high percentage of the disease and this is because most married women in the study area experience marriage at early ages of their lives, hence they are young and sexually active which is a predisposing factor for the acquisition of PID. This finding is in agreement with Ahmed et al. (2017) who stated $90 \%$ of women with PID cases are married and Shinde et al. (2018) who revealed that $79 \%$ of women with PID are married but this finding was in disagreement with the study of Nkwabong et al. (2016) who stated that $58.6 \%$ of the patients that had percentages of PID were singles compared to $41.6 \%$ of the patients who were married.

This study revealed that women in this study who are part of a polygamous family had higher rates of PID and this is due to the fact that the partners of most women in the polygamous family are exposed to multiple sexual partners and could be a potential carrier of pathogenic bacteria from one person to another which leads to PID. This finding is similar with the findings of Usman (2016) who stated that all the $66.7 \%$ of women studied were into polygamous family while $30.7 \%$ women were into monogamous family.

Basically, unemployed women in this study who had PID infection were high and this is based on the fact that most unemployed women are full housewives, illiterate and from a low socio-economic class, hence their ability to be well informed and updated on certain reproductive diseases and its preventive measures is not achieved. This finding agrees with Ahmed et al. (2017) who stated that out all PID cases sampled 90\% were unemployed.
This study revealed that women who showed high occurrence of PID infection were illiterates and since most of these women sampled are settled in the rural areas where education which prepares people on the preventive measures of a disease and assist people to use health services effectively is not encouraged especially for females. This finding is in agreement with Naaz (2016) and Ahmed et al. (2017) stated that women who were sampled with PID infection revealed high percentages of illiterates such as $30 \%$ and $60 \%$ respectively.

This study revealed that women who practiced douching daily had high percentage of PID compared to women who do not douche. This result is due to the fact that the frequency of douching among most women is high and such consistent practice is said to alter a woman's microflora of the vagina area, thereby supporting the growth of pathogenic microbes especially anaerobes which are causative agents of most PID case. This finding is in agreement with Usman (2016) and Short et al. (2015) who revealed that high percentages of women with PID practice douching.

This study also reveals that women who used water and soap for douching had higher percentages of PID and this could be because of consistent use of soap which is a compound of various chemicals cause genetic mutation in some or all the microbes in a vaginal region. Such mutation therefore influences the virulence of these organisms which causes the organisms to be pathogenic in their patients. In addition to this, water used by most of these women during douching could be acquired from various water sources such as river (Table 15) which harbors numerous pathogenic bacteria and constant use of such river water exposes the women to numerous pathogens which are said to ascend from the lower genital tract to the upper genital tract. This finding is in agreement with the findings of Short (2015).

Women studied in these 9 Local Government Areas revealed that those who passed their waste products in the open environment had high prevalence of PID. This result is due to the fact that the open environment harbors many pathogenic microbes due to various activities of the wind, man and animals. Such microbes pose a danger to women who pass out their waste in the environment due to unavailability of adequate toilet facilities in the community. This finding disagrees with Usman (2016) who stated that $64 \%$ of the women sampled who used water system had high occurrence of PID while 24.3\% than the $11.7 \%$ of women sampled used pit latrine and open air.

This study revealed that women who showed high 
occurrence of PID were nonusers of birth controls. The reason is that this study was carried out in a developing country where the acceptance and sustenance of family planning by the women is low and it is due to the low socio-economic status of the women. This finding is in agreement with the findings of Ahmed et al. (2017). However, high number of women with PID who practiced birth control used more of intrauterine device compared to condoms and pills. This thereby brings about the introduction and invasion of pathogens from the constant use of intrauterine device into the female urogenitals and this in turn causes pelvic inflammatory disease (Table 18).

This study also revealed that women who practiced self medication had high percentage of PID compared to women who do not indulge in this practice. This is because most of these women sampled tend to irrationally use certain synthetic or herbal products which have therapeutic effects without the prescription of a health care provider. Such misuse of these products leads to a condition known as selective toxicity pressure will occur on the organisms, thereby subjecting the microorganisms to develop resistance to these therapeutic agents in use. This finding agrees with the findings of Dayal (2016).

\section{CONCLUSION}

This study revealed that the high socio-economic, cultural and demographic factors prevalent in the area studied have resulted to high rate of morbidity among the females, hence the high rate of pelvic inflammatory disease recorded among reproductive age females. Therefore, it is necessary that the government should provide certain basic fundamental human rights such as free education to females as well as free medical care, prevent early marriage and condemn pre-marital sex with multiple individuals to ensure that females especially the rural dwellers are not at risk to certain life threatening disease such as pelvic inflammatory disease.

\section{REFERENCES}

Ahmed, S., Parvin, S., Shaha, D., Begum, P., Sanjowal, L., Hassan, M. K., \& Mohammad A. K. (2017). Clinical profile of Pelvic Inflammatory Disease (PID). Faridpur Medical College Journal, 12(1), 25-30.

Dayal, S., Singh, A., Chaturvedi, V., Krishna, M., \& Gupta, V. (2016). Pattern of pelvic inflammatory disease in women who attended the tertiary care hospital among the rural population of North India. Muller Journal of Medical Science Resources, 7,100-104.

Einwalter, L. A., Ritchie, J. M., Ault, K. A., \& Smith, E. M. (2005). Gonorrhea and Chlamydia infection among women visiting family planning clinic: racial variation in prevalence and predictors. Perspective Sex
Reproductive Health, 37(3), 135-140.

Enwa, F. O., Iyamu, M. I., Eboigbe, C. I., \& Esimone, C. O. (2015). Prevalence of resistant strains of Streptococcus pneumoniae to Oxacillin, Ofloxacin and Rifampicin in Abraka South-South, Nigeria. Global Journal of Medical Research: Microbiology and Pathology, 15(4), 1.

French, C. E., Hughes, G., \& Nicholson, A. (2011). Estimates of the pelvic inflammatory disease diagnoses: Trends in England, 2000-2008. Sex Transmission Disease, 38.158-162.

Huang, C. C., Lin, S. Y., Chang, C. Y. Y., Lin, W. C., \& Chung, C. H. (2019). Association of pelvic inflammatory disease (PID) with ectopic pregnancy and preterm labor in Taiwan: A nationwide populationbased retrospective cohort study. PLoS ONE, 14(8), 50.

Idakwo, S. (2015). Bacterial profile and antimicrobial susceptibility pattern of cather and non-cather associated UTI in patients attending hospitals in Minna. A Published Thesis presented to the Department of Microbiology, Federal University of Technology Minna, Niger State. Pp. 28-37.

Kolo, S. (2016). Prevalence of bacteriological and parasitic infections in HIV children (2-16 years) in Niger State. A published thesis presented to the Department of Microbiology, Federal University of Technology Minna, Niger State. Pp. 58-79.

Meštrović, T. (2017). Pelvic inflammatory disease etiology. Retrieved May 23 ${ }^{\text {rd }}, 2018$ from https://www.newsmedical.net/medical .

Naaz, F., Khan, N., \& Mastan, A. (2016). Risk factors of pelvic inflammatory disease: A prospective study. Int. Journal of Herbal Medicine, 4(4), 129-133.

Nkwabong, E., \& Dingom, M. A. N. (2015). Acute pelvic inflammatory disease in Cameroon: A cross sectional descriptive study. African Journal of Reproductive Health, 19(4), 1-6.

Oseni, T. I. A., \& Odewale, M. A. (2017). Socioeconomic status of parents and the occurrence of pelvic inflammatory disease among undergraduates attending Irrua Specialist Teaching Hospital, Irrua, Edo State, Nigeria. Nigerian Postgraduate Medical Journal, 24(2), 114-120.

Pachori, R., \& Kulkarni, N. (2016). Epidermiological markers in pelvic inflammatory disease (PID) among the women of reproductive age group. European Journal of Biomedical and Pharmaceutical Science, 3(2), 193-196.

Saini, S. N., Gupta, N., Aparna, B. G., \& Arora, D. R. (2003). Roles of anaerobes in acute pelvic inflammatory disease. Indian Journal of Medical Microbiology, 21(3), 189-192.

Shinde, S. A., Shinde, U. S., \& Asher, G.S. (2018). Pelvic inflammatory disease (PID): A cross sectional 
prospective study at a tertiary care centre. Int. J. of Clinical Biomedical Research, 4(3), 61-64.

Short, V. L., Totten, P. A., Ness, R. B., Astete, S. G., Kelsey, S. F., Murray, P., \& Haggerty, C. L. (2015). The demographic, sexual health and behavioural correlates of Mycoplasma genitalium infection among women with clinically suspected pelvic inflammatory disease. Sex Transm. Infect, 86, 29-31.

Simms, I., Stephenson, J. M., \& Mallinson, H. (2006). Risk factors associated with pelvic inflammatory disease. Sexually Transmitted Infections, 82, 452-457.

Spencer, T. H. I., Umeh, P. O., Irokanulo, E., Baba, M. M., Spencer, B. B., Umar, A. I., Ardzard, S. A., Oderinde, S., \& Onoja O. (2014). Bacterial isolates associated with Pelvic Inflammatory Disease among female patients attending some hospitals in Abuja, Nigeria. African Journal of Infectious Disease, 8(1), 9-13.

Usman, M. (2016). Prevalence of polymicrobial pelvic inflammatory infection among women attending three general hospitals in Niger State, Nigeria. A published hesis presented to the Department of Microbiology, Federal University of Technology Minna, Niger State. Pp. 33-41. 